\title{
Economical analysis of a chemical heat pump system for waste heat recovery
}

\author{
Hakan Demir ${ }^{*}$ Özden Ağra, Ş. Özgür Atayılmaz \\ Yıldız Technical University, Istanbul, Turkey \\ * Corresponding author.Tel: +90 21238328 20,Fax: +90212 261 66 59,E-mail: hdemir@yildiz.edu.tr
}

\begin{abstract}
Industrial chemical heat pumps (ICHPs) provide an ability to capture low - grade heat rejected from industrial sources and to reuse the heat increased temperature in industrial processes. Also it can be used for residential heating, cooling, water heating and energy storage. Several temperature boost levels can be obtained according to chemical reaction couple chosen. It can be either single source system or dual source system connected with available reject heat source. Dual source system is more effective than single source system and higher output temperature levels can be obtained. Reject heat source temperature and desired temperature boost are important in chemical reaction couple selection. Chemical reaction couple must be chosen carefully to provide the highest efficiency in all candidate systems. Economical feasibility of industrial chemical heat pump can be determined after calculations according to heat pump capacity. In this study, economical analysis of an industrial chemical heat pump system was accomplished compared with a steam boiler. Economical calculations was carried out and curves that show the relations between investment cost and capacity of chemical heat pump, investment cost and capacity of steam boiler, reject heat capacity and net savings were obtained for waste heat capacities below $2000 \mathrm{~kW}$. It is determined that the chemical system is feasible if the waste heat capacity is higher than a certain value according to economical parameters and lifetime. Also, net gain increases almost linearly with increasing waste heat capacity.
\end{abstract}

Keywords: Chemical heat pump, Economical analysis, Waste heat

\section{Introduction}

Industrial chemical heat pumps can utilize waste heat at lower temperatures and use it at increased temperatures for industrial processes. An extensive literature study was performed by Wongsuwan et. al. [1]. Industrial chemical heat pumps requires up to one-fifteenth of electrical power input when compared to conventional vapor compression cycle heat pumps [2]. Chemical heat pumps consist of two different reactions which run at two different temperature levels [3]. For this aim, dehydrogenation of alcohols and hydrogenation of acetone can be used in chemical heat pumps [4]. The feasibility of the isopropanol/acetone/hydrogen chemical heat pump system was investigated theoretically by Gastauer and Kameyama [5]. Reverse reaction for isopropanol/acetone/hydrogen chemical heat pump system is

$$
\mathrm{CH}_{3}-\mathrm{CHOH}-\mathrm{CH}_{3} \leftrightarrow \mathrm{CH}_{3}-\mathrm{CO}-\mathrm{CH}_{3}+\mathrm{H}_{2}
$$

Dehydrogenation of isopropanol is endothermic reaction which occurs at $55-85{ }^{\circ} \mathrm{C}$ in liquid phase and hydrogenation is exothermic reaction and occurs at maximum $202{ }^{\circ} \mathrm{C}$ in gas phase. A typical isopropanol/acetone/hydrogen heat pump is given in Figure 1. In this study a comparative economical analysis was performed. Maximum $\mathrm{COP}_{\mathrm{t}}=\mathrm{Q}_{\text {out }} / \mathrm{Q}_{\text {in }}$ of the isopropanol/acetone/hydrogen heat pump is $18.2 \%$ depending on isopropanol concentration [6].

In this study, an economical analysis was conducted as a function of waste heat flux. Total costs including investment and operational and maintenance costs of the chemical heat pump system and the steam boiler is obtained. Net gain is defined as the difference between the total costs of the chemical heat pump system and the steam boiler. 


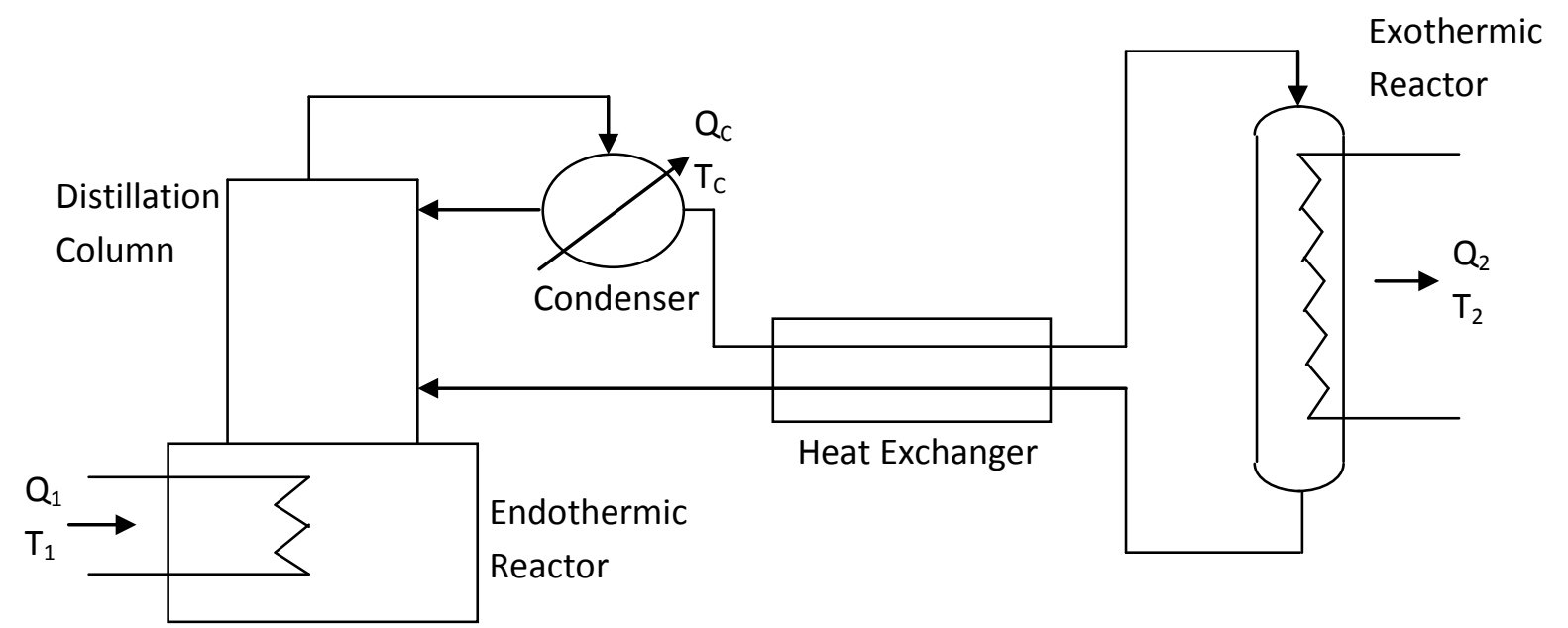

Figure 1 Isopropanol/acetone/hydrogen chemical heat pump flow diagram [5]

\section{Economical Analysis of Chemical Heat Pump System}

\subsection{Investment Cost}

Figure 2 derived from [7] can be used for determination of the investment cost of the chemical heat pump system.



Figure 2 Relationship between industrial chemical heat pump capacity and investment cost

The equation that gives the function in Figure 2 is of the form

$I_{C O}=-0.01832 Q^{2}+271.77 Q+75567.3$

where ICO is the investment cost $(\$)$ and Q is the capacity $(\mathrm{kW})$.

Figure $2 \mathrm{w}$ as obtained using economical values for 1988. In order to use it for the present calculations, it is required to make some modifications. For this aim a correction factor was defined as below: 
$f=\left(1+i_{1}\right)\left(1+i_{2}\right)\left(1+i_{3}\right) \ldots .\left(1+i_{n}\right)$

where i represents the inflation rate in corresponding year after 1988.

If the inflation rate is constant for all years from 1988 to the present, in that case;

$f=(1+i)^{n}$

$\mathrm{n}$ is the number of the years from 1988 to present. Then, the investment cost of the chemical heat pump system in the present year, $\mathrm{I}_{\mathrm{C}}(\$)$, is calculated from

$I_{C}=f . I_{C O}$

\subsection{Equivalent Annual Cost}

Equivalent annual cost is obtained as a function of interest rate, $i$ and lifetime of investment, $n$ (year) from

$E A C=I_{C} \frac{i(1+i)^{n}}{(1+i)^{n}-1}$

\subsection{Operating and Maintenance Cost}

Operating and maintenance cost of the chemical heat pump is calculated from [7]

$O M=\frac{E S . C E . O T}{16}+0.05 I_{C}$

Here, ES, CE and OT are equipment size $(\mathrm{kW})$, cost of electricity $(\$ / \mathrm{kWh})$ and operating time (h) respectively. The number 16 is used for industrial chemical heat pump which uses a fan to operate a cooling tower. If groundwater is used for cooling then a value of 20 should be used [7]. Maintenance cost is assumed 5\% of investment cost.

\subsection{Total Cost}

Total cost is the sum of the equivalent annual cost and operating and maintenance cost.

$T C=E A C+O M$

\section{Economical Analysis of Boiler}

\subsection{Investment Cost}

Investment cost is the price of a boiler which has the same thermal capacity as the chemical heat pump system. The investment cost of boiler was derived from present steam boiler prices available in the market. The variation of the boiler price $(\$)$ with thermal capacity $(\mathrm{kW})$ is given in Figure 3 and can be calculated from the Eq. 9 as a function of boiler capacity Q $(\mathrm{kW})$ for the capacities up to $2000 \mathrm{~kW}$.

$I_{C}=-0.00453216 Q^{2}+21.9991 Q+3367.2$

\subsection{Equivalent Annual Cost}

Equivalent annual cost is obtained as a function of interest rate, $\mathrm{i}$ and lifetime of investment, $\mathrm{n}$ (year) from 


$$
E A C=I_{C} \frac{i(1+i)^{n}}{(1+i)^{n}-1}
$$

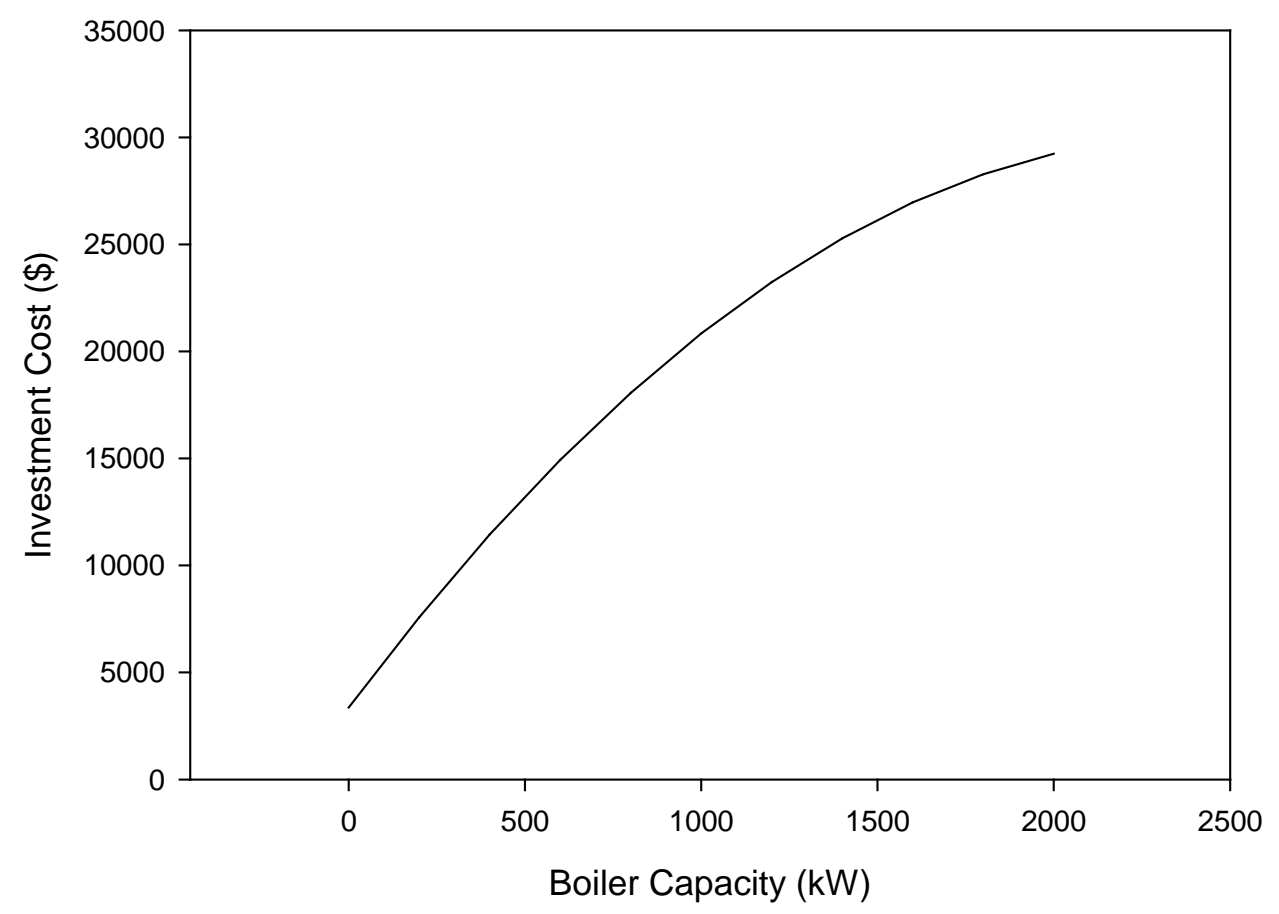

Figure 3 Relationship between boiler capacity and investment cost

\subsection{Annual Energy Consumption}

Annual energy consumption is the amount of fuel which is consumed during the operation of boiler and can be calculated from

$A E C=\frac{Q . O T}{\eta_{B} \cdot L H V}$

where $\eta_{\mathrm{B}}$ is the boiler efficiency and LHV is the lower heating value of fuel $(\mathrm{kJ} / \mathrm{kg})$. The cost of the annual energy consumption is

$A C=A E C . C F$

and $\mathrm{CF}$ is the cost of the fuel $(\$ / \mathrm{kg})$.

\subsection{Operating and Maintenance Cost}

Operating and maintenance cost of the boiler is calculated from

$O M=A C+0.05 I_{C}$

Maintenance cost is assumed 5\% of investment cost.

\subsection{Total Cost}

Total cost is the sum of the equivalent annual cost and operating and maintenance cost.

$T C=E A C+O M$ 


\section{Results}

Net gain is calculated from the difference between total costs of the chemical heat pump system and the boiler.

$N G=T C_{C H P}-T C_{B}$

where $\mathrm{TC}_{\mathrm{CHP}}$ and $\mathrm{TC}_{\mathrm{B}}$ are total annual costs of chemical heat pump and boiler respectively. The parameters used in the analysis are as below:

Waste heat flux, $550-11200 \mathrm{~kW}$

Effectiveness of chemical heat pump, 18\% [6]

ICHP capacity, $100-2000 \mathrm{~kW}$

Boiler efficiency, 90\%

Fuel, Fuel-Oil

Lower heating value of fuel, $39774.6 \mathrm{~kJ} / \mathrm{kg}$

Fuel price, $0.87 \$ / \mathrm{kg}$

Electricity price, $0.125 \$ / \mathrm{kWh}$

Inflation rate, $8 \%$

Operating time, $5475 \mathrm{~h} /$ year

Lifetime, $6-15$ years

Figure 4 represents the relation between ICHP capacity and net gain. It is seen that net gain increase almost linearly with increasing ICHP capacity.

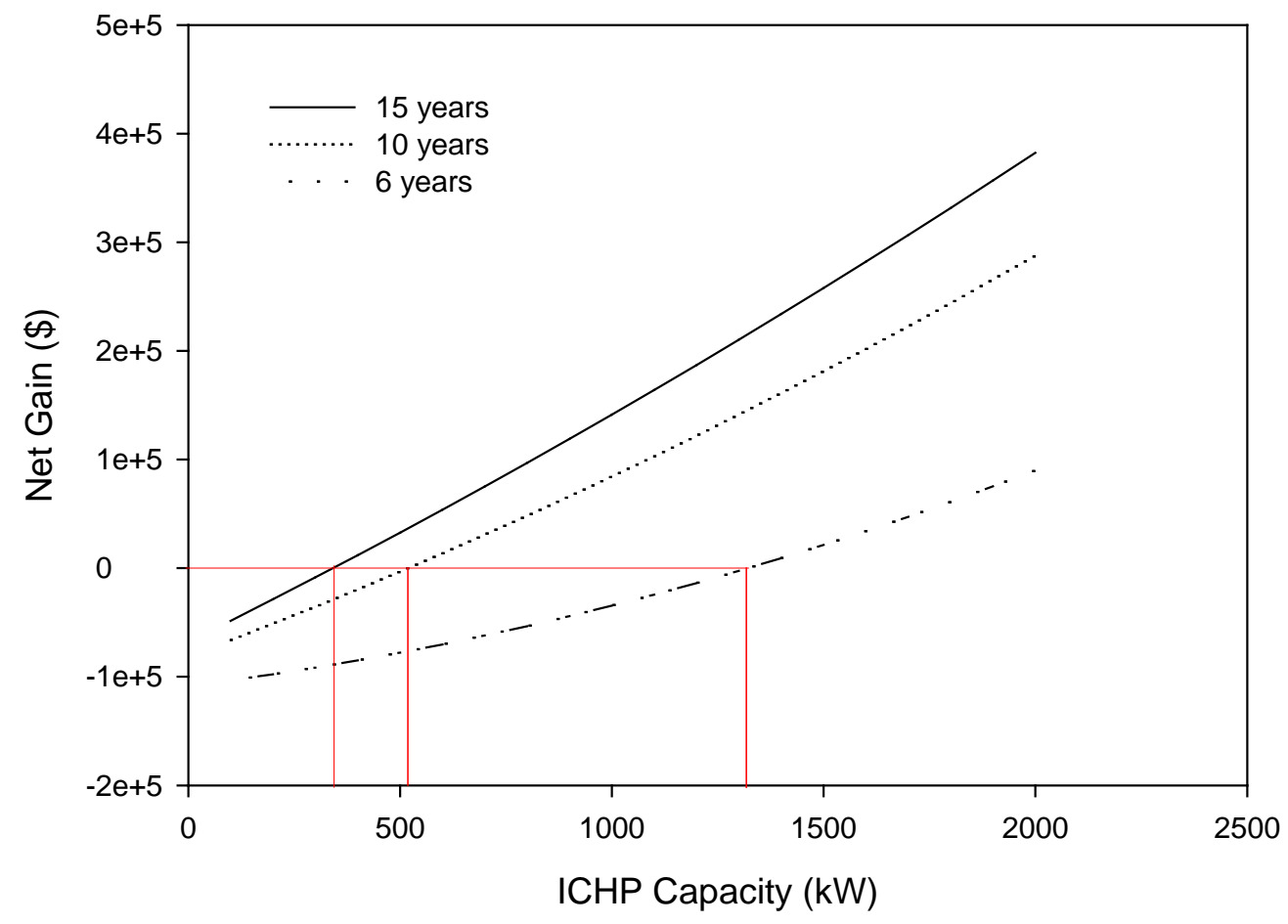

Figure 4 Relationship between ICHP capacity and net gain for lifetime 6, 10 and 15 years 


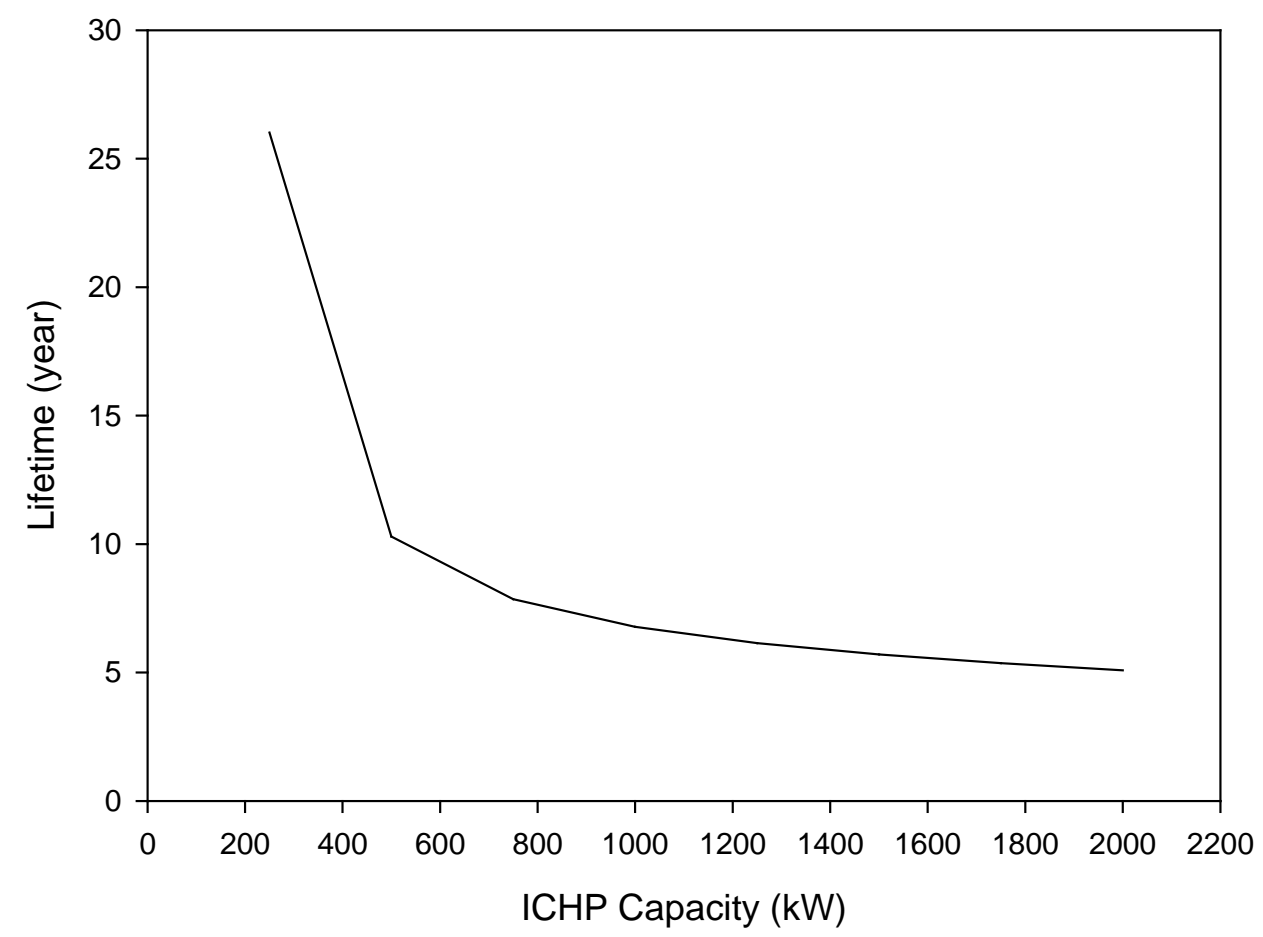

Figure 5 Relationship between ICHP capacity and lifetime where the net gain is zero

Figure 5 shows the relation between ICHP capacity and lifetime for zero net gain. It is seen that if the ICHP capacity is higher than $1000 \mathrm{~kW}$, lifetime is asymptotically approaches 5 years.

\section{Conclusion}

Economical feasibility of industrial chemical heat pumps can be determined after calculations according to heat pump capacity. Economical calculations were carried out and curves show the relations between investment cost and capacity of chemical heat pump, capital cost and capacity of steam boiler, ICHP capacity and net savings were obtained. It is determined that the chemical system is feasible if the waste heat capacity is higher than a certain value according to lifetime of investment. Also, net gain increases linearly with increasing waste heat capacity. In Figure 5, the upper region of the net gain zero curve shows the feasible zone and it is seen that the payback period is almost constant for the capacities higher than 1000 $\mathrm{kW}$.

\section{References}

[1] Wongsuwan, W., Kumar, S., Neveu, P., Meunier, F., A review of chemical heat pump technology and applications, Applied Thermal Engineering 21, 2001, pp. 1489-1519

[2] Clark , E . C., Industrial Chemical Heat Pumps: Chemically Driven, Rocket research Company, Washington, 1982

[3] Raldow, W. M., Wentworth , W. E., Chemical Heat Pumps - A Basic Thermodynamic Analysis, Solar Energy 23, 1979, pp. 75-79

[4] Prevost, M. ve Bugarel, R., "Chemical Heat Pumps: System Isopropanol - Acetone Hydrogen", Instut du Genie Chimique 
[5] Gastauer, P., Kameyama, H., The thermal efficiency of the isopropanol/acetone/hydrogen chemical heat pump: analysis and improvement, Proceedings of International Hydrogen and Clean Energy Symposium 1995, pp. 317-320

[6] Demir, H., Industrial Chemical Heat Pumps, MSc Thesis, Yıldız Technical University, 1999

[7] Clark, E. C., ICHP Economic Analysis, Rocket research Company, Washington, 1990

[8] Aybers , N., Şahin , B., Enerji Maliyeti, Yıldız Technical University, 1995 